Research Article

\title{
Epistasis interaction of QTL effects as a genetic parameter influencing estimation of the genetic additive effect
}

\author{
Jan Bocianowski \\ Department of Mathematical and Statistical Methods, Poznan University of Life Sciences, Poznan, Poland.
}

\begin{abstract}
Epistasis, an additive-by-additive interaction between quantitative trait loci, has been defined as a deviation from the sum of independent effects of individual genes. Epistasis between QTLs assayed in populations segregating for an entire genome has been found at a frequency close to that expected by chance alone. Recently, epistatic effects have been considered by many researchers as important for complex traits. In order to understand the genetic control of complex traits, it is necessary to clarify additive-by-additive interactions among genes. Herein we compare estimates of a parameter connected with the additive gene action calculated on the basis of two models: a model excluding epistasis and a model with additive-by-additive interaction effects. In this paper two data sets were analysed: 1) 150 barley doubled haploid lines derived from the Steptoe $\times$ Morex cross, and 2) $145 \mathrm{DH}$ lines of barley obtained from the Harrington $\times$ TR306 cross. The results showed that in cases when the effect of epistasis was different from zero, the coefficient of determination was larger for the model with epistasis than for the one excluding epistasis. These results indicate that epistatic interaction plays an important role in controlling the expression of complex traits.
\end{abstract}

Keywords: additive gene action effect, barley, doubled haploid lines, epistasis, QTL.

Received: July 16, 2012; Accepted: December 12, 2012.

\section{Introduction}

Epistasis (an additive-by-additive interaction between quantitative trait loci or a nonallelic interaction of homozygous loci) was recognized as early as 100 years ago by Bateson (1909) to describe a situation where the action of one locus masks the allelic effects at another locus. However, in classical statistical genetics, epistasis has been used as a statistical abstraction, so that less attention has been paid to the molecular and physiological nature of the gene interaction involved (Tachida and Cockerham, 1989).

Epistatic interactions of major genes, denoted as $a a$ (Kearsey and Pooni, 1998), have often been inferred from modified segregation ratios (Eshed and Zamir, 1996). For genes affecting quantitative traits epistasis has been defined as a deviation from the sum of independent effects of individual genes (Falconer, 1989). Epistasis between quantitative trait loci (QTLs) assayed in populations segregating for an entire genome has been found at a frequency close to that expected by chance alone (Edwards et al., 1987; Doebley and Stec, 1991; Paterson et al., 1991; Stuber et al., 1992; De-Vicente and Tanksley, 1993; Lin et al., 1995; Xiao et al., 1995). Recently epistatic effects have been considered by many researchers as important for complex traits

Send correspondence to Jan Bocianowski. Department of Mathematical and Statistical Methods, Poznan University of Life Sciences, Wojska Polskiego 28, 60-637 Poznan, Poland. E-mail: jboc@up.poznan.pl.
(Lark et al., 1995; Eshed and Zamir, 1996; Cockerham and Zeng, 1996; Yu et al., 1997; Conti et al., 2011; Gowda et al., 2011; Jiang et al., 2011; Li et al., 2011; Mao et al., 2011; Upadhyaya et al., 2011; Bocianowski, 2012a,b,c). Hence, genetic models for QTL mapping assuming no epistasis could lead to a biased estimation of QTL parameters.

A common problem reported so far as associated with the analyses of data is that analyses of single-locus QTLs and epistatic interactions were conducted separately using different analytical tools (Xing et al., 2002; Bocianowski, 2008, 2012a,b,c; Krajewski et al., 2012). Although both of the analytical tools can provide statistical estimates for the amount of the effects and the proportions of variance explained, it is necessary for a joint estimation to evaluate the relative importance of individual QTLs and epistatic interactions in determining the performance of these traits.

The aim of the current study was to compare estimates of a parameter connected with the additive gene action calculated on the basis of two models: a model excluding epistasis and a model with additive-by-additive interaction effects. To this end, two data sets were analysed: 1) 150 barley doubled haploid lines derived from the Steptoe $\times$ Morex cross, and 2) 145 doubled haploid lines of barley obtained from the HarringtonTR $\times 306$ cross. 


\section{Material and Methods}

\section{Estimation method}

If in an experiment $n$ biparental homozygous (doubled haploid, DH) plant lines were observed, an $n$-vector of phenotypic mean observations $\mathbf{y}=\left[\begin{array}{llll}y_{1} & y_{2} & \ldots & y_{n}\end{array}\right]$ ' and $q n$-vectors of marker genotype observations $\mathbf{m}_{l}, l=1,2, \ldots, q$ were obtained. The $i$-th element $(i=1,2, \ldots, \mathrm{n})$ of vector $\mathbf{m}_{l}$ is equal to -1 or 1 , depending on the parent's genotype exhibited by the $i$-th line.

The estimation of an additive effect of a QTL (denoted by $a$ ) is based on the assumption that genes responsible for the trait are closely linked to the observed molecular marker. By choosing $p$ from all the observed markers we can explain the variability of the trait, and model observations for the lines as:

$$
y=1 \mu+\mathbf{X} \beta+e,
$$

or

$$
y=1 \mu+\mathbf{X} \beta+\mathbf{Z} \gamma+\mathbf{e}
$$

where 1 denotes the $n$-dimensional vector of ones, $\mu$ the general mean, $\mathbf{X}$ a $(n \times p)$-dimensional matrix of the form $X=\left[\begin{array}{llll}\mathbf{m}_{l_{1}} & \mathbf{m}_{l_{2}} & \ldots & \mathbf{m}_{l_{p}}\end{array}\right], l_{1}, l_{2}, \ldots, l_{p} \in\{1,2, \ldots, q\}$ and $\boldsymbol{\beta}$ the $p$-dimensional vector of unknown parameters of the form $\boldsymbol{\beta}^{\prime}=\left[\begin{array}{llll}a_{l_{1}} & a_{l_{2}} & \ldots & a_{l_{p}}\end{array}\right]$. Finally, $\mathbf{Z}$ denotes a matrix whose columns are products of certain columns of matrix $\mathbf{X}, \boldsymbol{\gamma}$ is the vector of unknown parameters of the form $\gamma^{\prime}=\left[\begin{array}{llll}a a_{l_{1} l_{2}} & a a_{l_{1} l_{3}} & \ldots & a a_{l_{p-1} l_{p}}\end{array}\right]$, and e the $n$-dimensional vector of random variables, such that $E\left(e_{i}\right)=0, \operatorname{Var}\left(e_{i}\right)=\sigma^{2}$, and $\operatorname{Cov}\left(e_{i}, e_{j}\right)=0$ for $i \neq j, i, j=1,2, \ldots, n$. The parameters $a_{l_{1}}, a_{l_{2}}, \ldots, a_{l_{p}}$ are the additive effects of the genes controlling the trait and the parameters $a a_{l_{1} l_{2}}, a a_{l_{1} l_{3}}, \ldots, a a_{l_{p-1} l_{p}}$ are the additive $\times$ additive interaction effects. We assume that the epistatic interaction effects reveal only loci with significant additive gene action effects. This assumption significantly reduces the number of potential significant effects and improves the usefulness of the regression model.

The total additive effect of genes influencing the traits, defined as the sum of absolute values of individual additive effects, can be found in Bocianowski and Krajewski (2009) as:

$$
\hat{a}=\sum_{k=1}^{p}\left|\hat{a}_{l_{k}}\right|
$$

The total epistasis effect of gene pairs influencing the trait, defined as the sum of values of individual pairs effects, is given in Bocianowski (2012b) as:

$$
\hat{a} a=\sum_{k=1}^{p-1} \sum_{\substack{k^{\prime}=2 \\ k^{\prime} \neq k}}^{p} \hat{a} a_{l_{k} l_{k^{\prime}}}
$$

Markers chosen for models (1) and (2) may, for example, be selected, by a stepwise regression procedure (Charcosset et al., 2001). Here we used a three-stage algorithm, in which selection was first made by a backward stepwise search conducted independently within all linkage groups and then markers selected in this way were placed in one group and subjected to the second backward selection (see Jansen and Stam, 1994). Finally, at the third stage, we considered situations in which selected markers were located on the chromosome very close to each other (closer than $5 \mathrm{cM}$ ). Because these markers are probably linked to one QTL, only the marker with the largest value of the statistic test was retained in the set. At the first and second stages the Bonferroni correction was applied to control type I error for multiple tests (Province, 2001). For epistasis only markers showing significant association with traits were tested.

The coefficient of determination $\left(R^{2}\right)$ was used to measure how the model fits the data and, in this study, how the amount of the phenotypic variance is explained by the marker effects and marker interaction effects.

\section{Examples}

To compare the estimates of $a$ obtained by the two methods (excluding and including epistasis), the following data sets were used.

\section{Example 1}

The data concern 150 doubled haploid (DH) lines of barley obtained from the Steptoe $\times$ Morex cross, used in the North American Barley Genome Mapping (NABGM) project and tested in sixteen environments (Kleinhofs et al., 1993; Romagosa et al., 1996; GrainGenes database, Steptoe $\times$ Morex cross). The linkage map used consisted of 223 molecular markers, mostly RFLP, with a mean distance between markers of $5.66 \mathrm{cM}$. The lines were analysed for eight phenotypic traits (alpha amylase, AA; diastatic power, DP; grain protein, GP; grain yield, GY; height, H; heading date, HD; lodging, L; malt extract, ME; Hayes et al., 1993). Grain protein, lodging and malt extract were transformed by $\arcsin \sqrt{x / 100}$. Missing marker data were estimated by the method of Martinez and Curnow (1994), using non-missing data of flanking markers.

\section{Example 2}

The data also come from the NABGM project (Tinker et al., 1996; GrainGenes database, Hordeum) and concern 145 doubled haploid (DH) lines of barley obtained from the Harrington $\times$ TR306 cross. The lines were analysed for seven phenotypic traits (weight of grain harvested per unit area, GY; number of days from planting until emergence of $50 \%$ of heads on main tillers, HD; number of days from 
planting until physiological maturity, NM; plant height, $\mathrm{H}$; lodging transformed by $\arcsin \sqrt{x / 100}$, L; 1000 kernel weight, $\mathrm{KW}$; and test weight, TW). We used a map composed of 127 molecular markers (mostly RFLP) with the mean distance between markers of $10.62 \mathrm{cM}$. Results shown below concern observations from five environments (in four environments observations were made over two years).

The total additive effects of QTLs were estimated for model (1) - without epistasis and for model (2) - with epistasis, for each environment independently for both data sets.

\section{Results}

Table 1 presents estimates of the total additive effects for the 150 doubled haploid lines of barley obtained from the Steptoe $\times$ Morex cross calculated by an assumption of a lack of epistasis effect (model 1), as well as by an assumption of the effect of epistasis interactions of genes (model 2 ). The obtained results showed that in 27 cases (30\%) no

Table 1 - The total additive effect estimated on the basis of model (1) and model (2) for the 150 doubled haploid lines of barley obtained from the Steptoe $\times$ Morex cross (all epistasis effects are statistically significant at the 0.05 level).

\begin{tabular}{|c|c|c|c|c|c|c|c|c|c|}
\hline \multirow[t]{2}{*}{ Environment } & \multirow[t]{2}{*}{ Model } & \multicolumn{8}{|c|}{ Trait } \\
\hline & & AA & DP & GY & GP & HD & $\mathrm{H}$ & $\mathrm{L}$ & ME \\
\hline \multirow[t]{2}{*}{ ID91 ${ }^{\#}$} & (1) & 13.48 & 29.04 & 2.33 & 0.030 & 6.00 & 12.83 & - & 0.018 \\
\hline & (2) & 11.76 & 29.68 & 3.40 & 0.030 & 6.09 & 12.77 & - & 0.019 \\
\hline \multirow[t]{2}{*}{ ID92 } & (1) & 7.80 & 69.54 & 1.50 & 0.015 & 6.96 & 9.85 & - & 0.013 \\
\hline & (2) & 7.62 & 61.93 & 2.66 & 0.034 & 7.03 & 9.71 & - & 0.013 \\
\hline \multirow[t]{2}{*}{ MA92 } & (1) & - & - & 0.70 & - & 6.18 & 25.19 & 0.328 & - \\
\hline & (2) & - & - & 0.72 & - & 6.26 & 24.94 & 0.380 & - \\
\hline \multirow[t]{2}{*}{ MN92 } & (1) & 15.33 & 35.01 & 1.36 & 0.026 & 8.00 & 17.67 & - & 0.047 \\
\hline & (2) & 7.67 & 36.52 & 1.39 & 0.026 & 8.00 & 17.67 & - & 0.046 \\
\hline \multirow[t]{2}{*}{ MTd91 } & (1) & - & - & 1.17 & - & 5.56 & 9.88 & - & - \\
\hline & (2) & - & - & 1.13 & - & 5.71 & 9.88 & - & - \\
\hline \multirow[t]{2}{*}{ MTd92 } & (1) & 5.45 & 50.21 & 1.06 & 0.028 & 5.63 & 13.90 & 0.457 & 0.034 \\
\hline & (2) & 5.47 & 54.64 & 1.00 & 0.028 & 5.63 & 13.73 & 0.468 & 0.035 \\
\hline \multirow[t]{2}{*}{ MTi91 } & (1) & 4.95 & 51.06 & 1.67 & 0.042 & 5.94 & 18.76 & - & 0.023 \\
\hline & (2) & 5.04 & 48.80 & 1.57 & 0.039 & 5.45 & 18.59 & - & 0.023 \\
\hline \multirow[t]{2}{*}{ MTi92 } & (1) & 15.36 & 30.01 & 0.65 & 0.021 & 4.63 & 18.40 & 0.631 & 0.025 \\
\hline & (2) & 17.64 & 43.52 & 0.65 & 0.051 & 4.66 & 18.19 & 0.644 & 0.025 \\
\hline \multirow[t]{2}{*}{ NY92 } & (1) & - & - & 1.24 & - & 7.59 & 18.68 & 0.331 & - \\
\hline & (2) & - & - & 1.24 & - & 7.57 & 17.21 & 0.328 & - \\
\hline \multirow[t]{2}{*}{ ON92 } & (1) & - & - & 0.94 & - & 4.24 & 6.18 & 0.349 & - \\
\hline & (2) & - & - & 1.28 & - & 6.22 & 6.18 & 0.349 & - \\
\hline \multirow[t]{2}{*}{ OR91 } & (1) & 8.44 & 42.02 & 1.37 & 0.013 & 4.12 & 12.71 & - & 0.028 \\
\hline & (2) & 8.61 & 40.55 & 1.37 & 0.013 & 8.04 & 12.71 & - & 0.028 \\
\hline \multirow[t]{2}{*}{ SKg92 } & (1) & - & - & 1.30 & - & 6.65 & 16.97 & - & - \\
\hline & (2) & - & - & 1.77 & - & 6.65 & 17.30 & - & - \\
\hline \multirow[t]{2}{*}{ SKg93 } & (1) & - & - & 0.60 & - & 6.18 & 19.40 & - & - \\
\hline & (2) & - & - & 1.30 & - & 6.16 & 19.40 & - & - \\
\hline \multirow[t]{2}{*}{ SKo92 } & (1) & - & - & 0.95 & - & 4.99 & 13.16 & 0.383 & - \\
\hline & (2) & - & - & 0.95 & - & 4.75 & 13.16 & 0.387 & - \\
\hline \multirow[t]{2}{*}{ WA91 } & (1) & 7.51 & 21.84 & 1.43 & 0.022 & 5.53 & 15.92 & - & 0.027 \\
\hline & (2) & 7.51 & 21.84 & 1.44 & 0.023 & 5.53 & 16.00 & - & 0.027 \\
\hline \multirow[t]{2}{*}{ WA92 } & (1) & 5.04 & 32.56 & 0.65 & 0.026 & 5.07 & 20.35 & - & 0.027 \\
\hline & (2) & 5.13 & 49.03 & 1.22 & 0.026 & 5.05 & 21.20 & - & 0.028 \\
\hline
\end{tabular}

\footnotetext{
\#Abbreviations: ID91 - Aberdeen, Idaho, 1991; ID92 - Tetonia, Idaho, 1992; MA92 - Brandon, Manitoba, 1992; MN92 - Crookston, Minnesota, 1992; MTd91 - Bozeman, Montana, dry, 1991; MTd92 - Bonzeman, Montana, dry, 1992; MTi91 - Bozeman, Montana, irrigated, 1991 ; MTi92 - Bozeman, Montana, irrigated, 1992; NY92 - Ithaca, New York, 1992; ON92 - Guelph, Ontario, 1992; OR91 - Klamath Falls, Oregon, 1991 ; Kg92 - Goodlae, Saskatchewan, 1992; SKg93 - Kcfr, Saskatchewan, 1992; SKo92 - Outlook, Saskatchewan, 1992; WA91 - Pullman, Washington, 1991 ; WA92 - Pullman, Washington, 1992.
} 
statistically significant epistasis interaction effects were found. In 24 cases the values of additive effects were lower after epistasis had been incorporated in the model, compared to the case when this effect was excluded. The largest decrease of values of additive effects was observed for AA in MN92 - by 49.97\% (Table 1). In 39 cases, allowance for the epistasis effect caused an increase in the value of additive effects (Table 1). The largest increase of $a$ amounted to $142.86 \%$ (for GP in MTi92). The percentage phenotypic variance explained by QTL effects and their epistasis effects was larger than $R^{2} 100$ for model (1), except for one case, ME in MN92, where the decrease amounted to $0.3 \%$ (Table 2). The maximal increase of the observed phenotypic variation was $16.6 \%$ (from $25.2 \%$ to $41.8 \%$ for GY in
WA92). In ten cases, an increase in $R^{2}$ was observed, amounting to at least $10 \%$ (Table 2).

For the second dataset (146 doubled haploid lines of barley obtained from the HarringtonTR $\times 306$ cross), no epistasis effects were found in 38 cases (Table 3 ). With the incorporation of the effect of epistasis interaction in 14 cases, an increase of additive effect value and a reduction in the value of $a$ was denoted in 11 cases (Table 3 ). The largest reduction in the value of parameter $a$ was $46.10 \%$ (for $\mathrm{H}$ in MB93), whereas the largest increase of an additive effect was $28.88 \%$ (for WG in QC93). In all the cases, when the effect of epistasis was different from zero, the coefficient of determination was larger for model (2) than for model (1).

Table 2 - Percentage phenotypic variance $\left(R^{2} 100\right.$ [in \%]) explained by QTL effects (for model 1) and by QTL effects and their epistasis effects (for model 2) for 150 doubled haploid lines of barley obtained from the Steptoe $\times$ Morex cross.

\begin{tabular}{|c|c|c|c|c|c|c|c|c|c|}
\hline \multirow[t]{2}{*}{ Environment } & \multirow[t]{2}{*}{ Model } & \multicolumn{8}{|c|}{ Trait } \\
\hline & & $\mathrm{AA}$ & DP & GY & GP & HD & $\mathrm{H}$ & $\mathrm{L}$ & $\mathrm{ME}$ \\
\hline \multirow[t]{2}{*}{ ID91 } & (1) & 40.9 & 50.9 & 40.5 & 36.5 & 74.5 & 56.8 & - & 33.6 \\
\hline & (2) & 51.7 & 55.6 & 55.3 & 36.5 & 75.5 & 58.1 & - & 35.4 \\
\hline \multirow[t]{2}{*}{ ID92 } & (1) & 36.6 & 67.4 & 50.1 & 36.5 & 76.2 & 32.4 & - & 26.2 \\
\hline & (2) & 39.3 & 73.4 & 60.4 & 46.6 & 76.5 & 34.2 & - & 26.2 \\
\hline \multirow[t]{2}{*}{ MA92 } & (1) & - & - & 37.0 & - & 75.2 & 80.9 & 62.8 & - \\
\hline & (2) & - & - & 37.9 & - & 75.7 & 81.8 & 63.0 & - \\
\hline \multirow[t]{2}{*}{ MN92 } & (1) & 40.5 & 34.4 & 28.3 & 11.1 & 78.1 & 61.5 & - & 17.8 \\
\hline & (2) & 47.7 & 43.5 & 29.6 & 11.1 & 78.1 & 61.5 & - & 17.5 \\
\hline \multirow[t]{2}{*}{ MTd91 } & (1) & - & - & 63.7 & - & 68.9 & 48.4 & - & - \\
\hline & (2) & - & - & 66.4 & - & 71.1 & 48.4 & - & - \\
\hline \multirow[t]{2}{*}{ MTd92 } & (1) & 37.5 & 57.1 & 33.8 & 54.9 & 73.9 & 53.3 & 41.9 & 42.5 \\
\hline & (2) & 39.8 & 67.9 & 39.0 & 54.9 & 73.9 & 55.4 & 43.1 & 44.9 \\
\hline \multirow[t]{2}{*}{ MTi91 } & (1) & 18.8 & 66.5 & 47.9 & 31.7 & 68.7 & 61.5 & - & 36.8 \\
\hline & (2) & 20.0 & 75.4 & 52.4 & 37.6 & 73.3 & 63.2 & - & 36.8 \\
\hline \multirow[t]{2}{*}{ MTi92 } & (1) & 52.5 & 51.8 & 26.5 & 38.2 & 76.6 & 61.3 & 41.2 & 40.3 \\
\hline & (2) & 59.9 & 67.1 & 26.5 & 48.2 & 77.2 & 63.5 & 42.3 & 40.3 \\
\hline \multirow[t]{2}{*}{ NY92 } & (1) & - & - & 30.4 & - & 80.0 & 48.2 & 53.2 & - \\
\hline & (2) & - & - & 30.4 & - & 80.5 & 51.3 & 54.1 & - \\
\hline \multirow[t]{2}{*}{ ON92 } & (1) & - & - & 24.7 & - & 12.9 & 35.9 & 23.7 & - \\
\hline & (2) & - & - & 32.8 & - & 16.4 & 35.9 & 23.7 & - \\
\hline \multirow[t]{2}{*}{ OR91 } & (1) & 52.7 & 42.7 & 13.1 & 22.4 & 47.5 & 26.5 & - & 40.0 \\
\hline & (2) & 54.7 & 48.3 & 13.1 & 22.4 & 55.9 & 26.5 & - & 40.0 \\
\hline \multirow[t]{2}{*}{ SKg92 } & (1) & - & - & 37.4 & - & 78.7 & 53.0 & - & - \\
\hline & (2) & - & - & 48.0 & - & 78.7 & 56.7 & - & - \\
\hline \multirow[t]{2}{*}{ SKg93 } & (1) & - & - & 38.4 & - & 83.4 & 75.1 & - & - \\
\hline & (2) & - & - & 45.9 & - & 84.0 & 75.1 & - & - \\
\hline \multirow[t]{2}{*}{ SKo92 } & (1) & - & - & 19.7 & - & 61.4 & 57.5 & 44.8 & - \\
\hline & (2) & - & - & 19.7 & - & 63.6 & 57.5 & 46.6 & - \\
\hline \multirow[t]{2}{*}{ WA91 } & (1) & 27.6 & 39.6 & 54.9 & 39.8 & 67.3 & 67.6 & - & 31.5 \\
\hline & (2) & 27.6 & 39.6 & 55.9 & 42.4 & 67.3 & 68.1 & - & 31.5 \\
\hline \multirow[t]{2}{*}{ WA92 } & (1) & 43.2 & 53.2 & 25.2 & 40.4 & 77.3 & 62.4 & - & 45.5 \\
\hline & (2) & 44.1 & 68.4 & 41.8 & 40.4 & 77.8 & 68.1 & - & 48.1 \\
\hline
\end{tabular}

${ }^{\#}$ Abbreviations as in Table 1. 
Table 3 - The total additive effect estimated on the basis of model (1) excluding epistasis and on the basis of model (2) including epistasis for 145 doubled haploid lines of barley obtained from the Harrington x TR306 cross (all epistasis effects, except for TW in SK92a, are statistically significant at the 0.05 level).

\begin{tabular}{|c|c|c|c|c|c|c|c|c|}
\hline \multirow[t]{2}{*}{ Environment } & \multirow[t]{2}{*}{ Model } & \multicolumn{7}{|c|}{ Trait } \\
\hline & & WG & $\mathrm{NH}$ & NM & $\mathrm{H}$ & $\mathrm{L}$ & KW & TW \\
\hline \multirow[t]{2}{*}{ ON92a\# } & (1) & 118.1 & 1.57 & 2.77 & 5.68 & 0.031 & 4.85 & 3.41 \\
\hline & (2) & 118.2 & 1.57 & 2.41 & 6.84 & 0.025 & 4.85 & 3.41 \\
\hline \multirow[t]{2}{*}{ ON93a } & (1) & 81.66 & 1.47 & 1.17 & 11.79 & 0.050 & 4.20 & 1.21 \\
\hline & (2) & 81.66 & 1.47 & 1.24 & 12.20 & 0.050 & 4.20 & 1.21 \\
\hline \multirow[t]{2}{*}{ ON92b } & (1) & 89.62 & 1.79 & 0.61 & 3.61 & 0.308 & 1.25 & 5.36 \\
\hline & (2) & 93.84 & 1.85 & 0.61 & 3.61 & 0.299 & 1.25 & 5.46 \\
\hline \multirow[t]{2}{*}{ ON93b } & (1) & 61.75 & 0.48 & 0.34 & 3.69 & 0.367 & 4.65 & 4.44 \\
\hline & (2) & 60.47 & 0.48 & 0.34 & 3.75 & 0.299 & 4.65 & 4.66 \\
\hline \multirow[t]{2}{*}{ MB92 } & (1) & 44.28 & 2.14 & 2.87 & 2.97 & 0.045 & 4.88 & 1.05 \\
\hline & (2) & 44.28 & 2.13 & 2.85 & 2.97 & 0.045 & 4.78 & 1.05 \\
\hline \multirow[t]{2}{*}{ MB93 } & (1) & 83.55 & 3.88 & 1.92 & 10.65 & 0.259 & 5.26 & 6.61 \\
\hline & (2) & 83.55 & 4.02 & 1.92 & 5.74 & 0.258 & 5.26 & 4.40 \\
\hline \multirow[t]{2}{*}{ QC93 } & (1) & 35.15 & 2.23 & 1.36 & 3.96 & 0.307 & 2.48 & 0.79 \\
\hline & (2) & 45.30 & 2.21 & 1.36 & 3.96 & 0.307 & 2.48 & 0.79 \\
\hline \multirow[t]{2}{*}{ SK92a } & (1) & 56.09 & 1.89 & 1.66 & 5.70 & 0.065 & 2.23 & $0.00^{\mathrm{ns}}$ \\
\hline & (2) & 56.09 & 1.89 & 1.66 & 5.70 & 0.065 & 2.23 & $0.00^{\mathrm{ns}}$ \\
\hline \multirow[t]{2}{*}{ SK93a } & (1) & 99.05 & 1.70 & 1.20 & 2.48 & 0.147 & 7.16 & 4.62 \\
\hline & (2) & 99.05 & 1.70 & 1.20 & 2.48 & 0.139 & 7.13 & 4.62 \\
\hline
\end{tabular}

ns - not statistically significant.

\#Abbreviations: ON92a - Ailsa Craig, Ontario, 1992; ON93a - Ailsa Craig, Ontario, 1993; ON92b - Elora, Ontario, 1992; ON93b - Elora, Ontario, 1993; MB92 - Brandon, Manitoba, 1992; MB93 - Brandon, Manitoba, 1993; QC93 - Ste-Anne-de-Bellevue, Quebec, 1993; SK92a - Outlook, Saskatchewan, 1992; SK93a - Outlook, Saskatchewan, 1992.

The largest increase in the $R^{2}$ value, amounting to $11.0 \%$, was observed for L in ON93b (Table 4).

\section{Discussion}

The identification of QTLs and the elucidation of their genetic control (main effects and their epistatic effects) are essential for the development of efficient marker-assisted selection (MAS), aimed at improving breeding efficiency (Govindaraj et al., 2009). A direct implication of epistasis, especially the involvement of QTLs in epistatic interactions, is that the effects of single-locus QTLs are mostly dependent on the genotypes of other loci, and the effect of a QTL can sometimes be negated by the genotypes of a second locus. Thus any attempt to utilize QTLs in breeding programs has to take into account such epistatic effects. It is worthy of note that, although this study revealed a large number of epistases events through statistical genetic analysis, many further studies are needed before we can fully understand the biological meaning of these phenomena.

The most-important results of this study relate to the statistical characterization of the genetic components that control the expression of the traits, including additive-byadditive epistatic interactions. Ma et al. (2007) observed that $37 \%$ of the main-effect QTLs were involved in the epistatic interactions in maize grain yield and its components. This indicated that many loci in epistatic effects might not have significant effects for studied trait alone but might affect its expression by epistatic effects with the other loci. The results obtained herein also suggest that some of the additive QTLs might be detected with effects confounded by epistatic effects, if the epistatic effects were ignored in QTL mapping.

Incorporation of epistasis interaction of QTLs provided a more comprehensive characterization of the analyzed DH lines. This is evidenced by the higher $R^{2}$ values for model (2) than for model (1), i.e. the one excluding epistasis (Tables 2 and 4). Thus it may be concluded that QTL epistasis is a significant component for the understanding of the genetic control of determined phenotypic values, while failure to include epistasis may result in an incomplete or even erroneous characterization of the analyzed. In the presence of epistasis, however, the control of only main-effect markers is insufficient, because the epistatic effects of QTLs will also show influences, particularly in the case of complex phenotypes (Li et al., 1997a,b). Thus, inclusion of interaction markers closely linked to epistatic QTLs in the statistical models is expected to im- 
Table 4 - Percentage phenotypic variance $\left(R^{2} 100\right.$ [in \%]) explained by QTL effects (for model 1) and by QTL effects and their epistasis effects (for model 2) for 145 doubled haploid lines of barley obtained from the Harrington $\times$ TR306 cross.

\begin{tabular}{|c|c|c|c|c|c|c|c|c|}
\hline \multirow[t]{2}{*}{ Environment } & \multirow[t]{2}{*}{ Model } & \multicolumn{7}{|c|}{ Trait } \\
\hline & & WG & $\mathrm{NH}$ & NM & $\mathrm{H}$ & $\mathrm{L}$ & KW & TW \\
\hline \multirow[t]{2}{*}{ ON92a\# } & (1) & 41.6 & 43.9 & 41.2 & 18.3 & 7.0 & 34.8 & 34.8 \\
\hline & (2) & 47.7 & 43.9 & 47.2 & 18.5 & 9.2 & 34.8 & 34.8 \\
\hline \multirow[t]{2}{*}{ ON93a } & (1) & 36.6 & 39.8 & 25.3 & 31.0 & 4.1 & 42.2 & 14.6 \\
\hline & (2) & 36.6 & 39.8 & 28.6 & 34.3 & 4.1 & 42.2 & 14.6 \\
\hline \multirow[t]{2}{*}{ ON92b } & (1) & 28.0 & 42.7 & 14.0 & 20.4 & 28.3 & 16.2 & 43.5 \\
\hline & (2) & 29.9 & 46.7 & 14.0 & 20.4 & 29.7 & 16.2 & 44.6 \\
\hline \multirow[t]{2}{*}{ ON93b } & (1) & 50.5 & 23.5 & 11.6 & 26.8 & 34.2 & 32.8 & 34.3 \\
\hline & (2) & 54.8 & 23.5 & 11.6 & 27.9 & 45.2 & 32.8 & 36.8 \\
\hline \multirow[t]{2}{*}{ MB92 } & (1) & 21.6 & 43.2 & 45.4 & 20.8 & 9.6 & 29.1 & 20.0 \\
\hline & (2) & 21.6 & 44.3 & 48.4 & 20.8 & 9.6 & 30.5 & 20.0 \\
\hline \multirow[t]{2}{*}{ MB93 } & (1) & 39.1 & 48.6 & 33.4 & 46.1 & 23.7 & 55.8 & 51.1 \\
\hline & (2) & 39.1 & 50.9 & 33.4 & 48.1 & 25.9 & 55.8 & 54.8 \\
\hline \multirow[t]{2}{*}{ QC93 } & (1) & 32.7 & 42.4 & 25.5 & 21.0 & 22.0 & 39.0 & 16.2 \\
\hline & (2) & 32.7 & 45.4 & 27.5 & 21.0 & 22.0 & 39.0 & 16.2 \\
\hline \multirow[t]{2}{*}{ SK92a } & (1) & 10.8 & 27.6 & 16.8 & 15.8 & 4.7 & 17.1 & 0.0 \\
\hline & (2) & 10.8 & 27.6 & 16.8 & 15.8 & 4.7 & 17.1 & 0.0 \\
\hline \multirow[t]{2}{*}{ SK93a } & (1) & 27.4 & 30.4 & 22.7 & 18.6 & 17.6 & 68.1 & 54.2 \\
\hline & (2) & 27.4 & 30.4 & 22.7 & 18.6 & 20.2 & 70.5 & 54.2 \\
\hline
\end{tabular}

${ }^{\#}$ Abbreviations as in Table 3.

prove the power and accuracy of QTL mapping. The phenomenon of a biased estimation of additive effects in the absence of important interaction effects has already been addressed by Zeng et al. (2005) in the analysis of simulation data. A significant proportion of the identified additive effect QTLs were involved in digenic interactions with background loci. Thus, the usual estimates of additive effects of a QTL can be confounded by interactions, which may change according to genetic backgrounds, environments, and other factors. This means that QTLs and the epistatic loci are interchangeable, depending on the genetic backgrounds and probably environments where they are identified. This study showed that, besides the main (additive) effect QTLs, epistatic QTLs also play a crucial role in determining phenotypic values. Even if the epistatic interactions of main effect QTLs limit their usefulness in MAS programmes (Tan et al., 2001), the pronounced individual additive effects of these QTLs are sufficient enough to recruit them for MAS (Govindaraj et al., 2009). Because of the interaction between different loci, the offspring phenotype will be largely influenced by the genetic background of the receptor line when marker-directed selection is carried out (Tan et al., 2001).

The results obtained herein reinforce the importance of epistasis investigations in marker trait association studies, as the individual effect of a marker as locus depends on the marker genotype at other interacting loci. In fact, a fa- vorable allele at one locus may be an unfavorable one in a different genetic background, and vice versa (Holland, 2001). Thus, this has to be taken in consideration, especially for sugarcane, due to the several possible interactions between the multiple alleles from different loci.

Furthermore, the results indicate that epistatic interaction plays an important role in controlling the expression of complex traits. Yu et al. (1997) and Rahman et al. (2007) also identified a number of epistatic QTLs influencing yield and yield components. Thus, the utilization of marker assisted selection in different plant breeding programs has to take epistatic effects into consideration.

\section{References}

Bateson W (1909) Mendel's Principles of Heredity. Cambridge University Press, Cambridge, 396 pp.

Bocianowski J (2008) Comparison of two methods of estimation of nonallelic interaction of QTL effects on the basis of doubled haploid lines in barley. Agric Conspec Sci 73:183-187.

Bocianowski J (2012a) A comparison of two methods to estimate additive-by-additive interaction of QTL effects by a simulation study. J Theor Biol 308:20-24.

Bocianowski J (2012b) Analytical and numerical comparisons of two methods of estimation of additive $\times$ additive interaction of QTL effects. Sci Agric 69:240-246.

Bocianowski J (2012c) Using weighted multiple linear regression in estimation of QTL-by-QTL epistasis effects. Genet Mol Biol 35:802-809. 
Bocianowski J and Krajewski P (2009) Comparison of the genetic additive effect estimators based on phenotypic observations and on molecular marker data. Euphytica 165:113-122.

Charcosset A, Mangin B, Moreau L, Combes L, Jourjon M-F and Gallais A (2001) Heterosis in maize investigated using connected RIL populations. In: Gallais A, Dillmann C and Goldringer I (eds) Quantitative Genetics and Breeding Methods: The Way Ahead. Proceedings of the Eleventh Meeting of the EUCARPIA, Section Biometrics in Plant Breeding, Institut National de la Recherche Agronomique, Paris, France, Les Colloques 96, pp 89-98.

Cockerham CC and Zeng ZB (1996) Design with marker loci. Genetics 143:1437-1456.

Conti V, Roncallo PF, Beaufort V, Cervigni GL, Miranda R, Jensen CA and Echenique VC (2011) Mapping of main and epistatic effect QTLs associated to grain protein and gluten strength using a RIL population of durum wheat. J Appl Genet 52:287-298.

De-Vicente MC and Tanksley SD (1993) QTL analysis of transgressive segregation in an interspecific tomato cross. Genetics 134:585-596.

Doebley J and Stec A (1991) Genetic analysis of the morphological differences between maize and teosinte. Genetics 129:285-295

Edwards MD, Stuber CW and Wendel JF (1987) Molecularmarker-facilitated investigations of quantitative-trait loci in maize. I. Numbers, genomic distribution and types of gene action. Genetics 116:113-125.

Eshed Y and Zamir D (1996) Less-than-additive epistatic interactions of quantitative trait loci in tomato. Genetics 143:18071817.

Falconer DS (1989) Introduction to Quantitative Genetics. John Wiley and Sons, New York, 340 pp.

Govindaraj P, Vinod KK, Arumugachamy S and Maheswaran M (2009) Analysing genetic control of cooked grain traits and gelatinization temperature in a double haploid population of rice by quantitative trait loci mapping. Euphytica 166:165176.

Gowda SJM, Radzika P, Mhase LB, Jamadagni BM, Gupta VS and Kadro NY (2011) Mapping of QTLs governing agronomic and field traits in chickpea. J Appl Genet 52:9-21.

Hayes PM, Liu BH, Knapp SJ, Chen F, Jones B, Blake T, Franckowiak J, Rasmusson D, Sorrells M, Ullrich SE, et al. (1993) Quantitative trait locus effects and environmental interaction in a sample of North American barley germ plasm. Theor Appl Genet 87:392-401.

Holland J (2001) Epistasis and plant breeding. In: Janick J (ed) Plant Breeding Reviews. Vol. 21. John Wiley \& Sons, Inc., New York, pp 27-112.

Jansen RC and Stam P (1994) High resolution of quantitative traits into multiple loci via interval mapping. Genetics 136:1447-1455.

Jiang Z, Zhang B, Teng W, Han Y, Zhao X, Sun D, Zhang Z and Li W (2011). Impact of epistasis and QTL $\times$ environmental interaction on the oil filling rate of soybean seed at different developmental stages. Euphytica 177:431-442.

Kearsey MJ and Pooni HS (1998) The Genetical Analysis of Quantitative Traits. Chapman and Hall, London, 381 pp.

Kleinhofs A, Kilian A, Saghai Maroof MA, Biyashev RM, Hayes P, Chen FQ, Lapitan N, Fenwick A, Blake TK, Kanazin V, et al. (1993) A molecular, isozyme and morphological map of the barley (Hordeum vulgare) genome. Theor Appl Genet 86:705-712.

Krajewski P, Bocianowski J, Gawlowska M, Kaczmarek Z, Pniewski T, Swiecicki W and Wolko B (2012) QTL for field components and protein content: A multienvironmental study of two pea (Pisum sativum L.) populations. Euphytica 183:323-336.

Lark KG, Chase K, Adler FR, Mansur LM and Orf JJ (1995) Interactions between quantitative trait loci in soybean in which trait variation at one locus is conditional upon a specific allele at another. Proc Natl Acad Sci USA 92:4656-4660.

Li ZK, Pinson SRM, Park WD, Paterson AH and Stansel JW (1997a) Epistasis for three grain yield components in rice (Oryza sativa L.). Genetics 145:453-465.

Li ZK, Pinson SRM, Paterson AH, Park WD and Stansel JW (1997b) Genetics of hybrid sterility and hybrid breakdown in an inter-subspecific rice (Oryza sativa L.) population. Genetics 145:1139-1148.

Li Z-M, Ding J-Q, Wang R-X, Chen J-F, Sun X-D, Chen W, Song W-B, Dong H-F, Dai X-D, Xia Z-L, et al. (2011) A new QTL for resistance to Fusarium ear rot in maize. J Appl Genetics 52:403-406.

Lin Y, Schertz KF and Paterson AH (1995) Comparative analysis of QTLs affecting plant height and maturity across Poacceae, in reference to an interspecific sorghum population. Genetics 141:391-411.

Ma XQ, Tang JH, Teng WT, Yan JB, Meng YJ and Li JS (2007) Epistatic interaction is an important genetic basis of grain yield and its components in maize. Mol Breed 20:41-51.

Mao D, Liu T, Xu C, Li X and Xing Y (2011). Epistasis and complementary gene action adequately account for the genetic bases of transgressive segregation of kilo-grain weight in rice. Euphytica 180:261-271.

Martinez O and Curnow RN (1994) Missing markers when estimating quantitative trait loci using regression mapping. Heredity 73:198-206.

Paterson AH, Damon S, Hewitt JD, Zamir D, Rabinowitch HD, Lincoln SE, Lander ES and Tanksley SD (1991) Mendelian factors underlying quantitative traits in tomato: Comparison across species, generations and environments. Genetics 127:181-197.

Province MA (2001) 30 Sequential methods of analysis for genome scan. Advance in Genetics 42:499-514.

Rahman ML, Chu SH, Choi MS, Qiao YL, Jiang W, Piao R, Khanam S, Cho YI, Jeung J, Jena KK, et al. (2007) Identification of QTLs for some agronomic traits in rice using an introgression line from Oryza minuta. Mol Cells 24:16-26.

Romagosa I, Ullrich SE, Han F and Hayes PM (1996) Use of the additive main effects and multiplicative interaction model in QTL mapping for adaptation in barley. Theor Appl Genet 93:30-37.

Stuber CW, Lincoln SE, Wolff DW, Helentjaris T and Lander ES (1992) Identification of genetic factors contributing to heterosis in a hybrid from two elite maize inbred lines using molecular markers. Genetics 132:823-839.

Tachida H and Cockerham CC (1989) A building block model for quantitative genetics. Genetics 121:839-844.

Tan YF, Sun M, Xing YZ, Hua JP, Sun XL, Zhang QF and Corke H (2001) Mapping quantitative trait loci for milling quality, protein content and color characteristics of rice using a re- 
combinant inbred line population derived from an elite rice hybrid. Theor Appl Genet 103:1037-1045.

Tinker NA, Mather DE, Rossnagel BG, Kasha KJ, Kleinhofs A, Hayes PM, Falk DE, Ferguson T, Shugar LP, Legge WG, et al. (1996) Regions of the genome that affect agronomic performance in two-row barley. Crop Sci 36:1053-1062.

Upadhyaya HD, Sharma S, Singh S and Singh M (2011). Inheritance of drought resistance related traits in two crosses of groundnut (Arachis hypogaea L.). Euphytica 177:55-66.

Xiao J, Li J, Yuan L and Tanksley SD (1995) Dominance is the major genetic basis of heterosis in rice as revealed by QTL analysis using molecular markers. Genetics 140:745-754.

Xing YZ, Tan YF, Hua JP, Sun XL and Zhang Q (2002) Characterization of the main effects, epistatic effects and their environmental interactions of QTLs on the genetic basis of yield traits in rice. Theor Appl Genet 105:248-257.

Yu SB, Li JX, Xu CG, Tan YF, Gao YJ, Li XH, Zhang Q and Maroof MAS (1997) Importance of epistasis as the genetic basis of heterosis in an elite rice hybrid. Proc Natl Acad Sci USA 94:9226-9231.

Zeng Z-B, Wang T and Zou W (2005) Modeling quantitative trait loci and interpretation of models. Genetics 169:1711-1725.

\section{Internet Resources}

GrainGenes, a database for Triticeae and Avena: The Steptoe $\times$ Morex Barley Mapping Population, http://wheat.pw.usda.gov/ggpages/SxM (July 16, 2012).

GrainGenes, a database for Triticeae and Avena: Hordeum, http://wheat.pw.usda.gov/ggpages/maps/ Hordeum (July 16, 2012).

\section{Associate Editor: Dario Grattapaglia}

License information: This is an open-access article distributed under the terms of the Creative Commons Attribution License, which permits unrestricted use, distribution, and reproduction in any medium, provided the original work is properly cited. 